\title{
Correction to: Omeprazole Absorption and Fasting Gastrinemia After Roux-en-Y Gastric Bypass
}

\author{
Renata V. A. Collares-Pelizaro ${ }^{1}$ - José S. Santos ${ }^{1}$ - Carla B. Nonino ${ }^{2}$. \\ Larissa Alves dos Reis Dias ${ }^{3}$. Cristiane M. Gaitani ${ }^{4} \cdot$ Wilson Salgado Jr ${ }^{1}$
}

Published online: 18 October 2017

(C) Springer Science+Business Media, LLC 2017

Correction to: OBES SURG (2017) 27:2303-2307

https://doi.org/10.1007/s11695-017-2672-z

Larissa Alves dos Reis Dias was mistakenly included in the acknowledgment section of this article, and was mistakenly left out of the list of co-authors. The correct list of authors is shown above.

The online version of the original article can be found at https://oi.org/ $10.1007 / \mathrm{s} 11695-017-2672-\mathrm{z}$

Wilson Salgado, Jr

wsalgado@fmrp.usp.br

Renata V. A. Collares-Pelizaro

renatacollares@usp.br

José S. Santos

jsdsanto@ fmrp.usp.br

Carla B. Nonino

carla@fmrp.usp.br

Larissa Alves dos Reis Dias

larissad@fcfrp.usp.br

Cristiane M. Gaitani crisgai@ fcfrp.usp.br
Department of Surgery and Anatomy, Clinical Hospital, Faculty of Medicine, University of São Paulo, Ribeirão Preto, Brazil

Department of Clinical Analysis, Toxicology and Bromatology, Faculty of Pharmaceutical Sciences, University of São Paulo, Ribeirão Preto, Brazil

Department of Clinical Analysis, Toxicology and Bromatology, School of Pharmaceutical Sciences, University of São Paulo, Ribeirão Preto, Brazil

4 Nutritional Division of the Department of Medical Clinic, Clinical Hospital, Faculty of Medicine, University of São Paulo, Ribeirão Preto, Brazil 